\title{
Therapeutic Itinerary of People with Mental Diseases in the Service of Psychiatry of the Donka National Hospital, Conakry Hospital
}

\author{
Soumaoro $\mathrm{K}^{1}$, Keita $\mathrm{MM}^{2 *}$, Solo $\mathrm{C}^{3}$, Nansouma $\mathrm{K}^{4}$ and Doukouré $\mathbf{M}^{5}$ \\ ${ }^{1}$ Psychiatrist, Department of Psychiatry at Donka National Hospital - CHU Conakry \\ ${ }^{2}$ psychiatrist-addictologist, psychiatric department of Donka National Hospital, \\ Conakry University Hospital \\ ${ }^{3}$ Psychiatrist, Department of Psychiatry at Donka National Hospital - CHU Conakry \\ ${ }^{4}$ Doctor, psychiatric department of Donka National Hospital - CHU Conakry \\ ${ }^{5}$ Child psychiatrist, psychiatric ward of Donka National Hospital - CHU Conakry
}

\section{Research Article}

Volume 3 Issue 5

Received Date: April 18, 2018

Published Date: June 01, 2018

*Corresponding author: Dr. Mamady Mory Keita, Psychiatrist- Addictologist, Assistant Professor at the Faculty of Medicine, Gamal Abdel Nasser University of Conakry, Department of Psychiatry, Donka National Hospital, CHU of Conakry, Tel: (224) 628779717/657408760; Email: saramady1957@gmail.com

\section{Abstract}

Introduction: Our objectives in this study were to determine the frequency of people with mental illness admitted to the psychiatric department from another care structure, describe their demographic characteristics, identify the different care systems adopted by patients to know the motivations of the choice of treatment and identify methods supported. IT was a prospective, descriptive type of a six-month on 380 cases of therapeutic routes for people with mental illness in psychiatric ward of the National Hospital of Donka Hospital in Conakry.

Methods: We included in this study, patients of any age, any gender and from any source, regardless of the clinical presentation, admitted to the service during the study period, in which the existence of a psychiatric disorder was the reason for consultation in several care centers after agreeing to participate in the study.

Results: The frequency of individuals who used traditional medicine was $84 \%$, adolescents and young adults were much affected. Male patients, singles were the most affected with a sex ratio (M / F) 2.7 the majority had no profession, and the secondary level was the most affected with $45 \%, 24 \%, 18 \%, 13 \%$. The most frequent psychiatric comorbidities were: Bipolar disorder (43.6\%), substance use (31.5\%).

Conclusion: A broader general population study helps identify the extent of the problem of the itinerary of people with mental illness.

Keywords: Therapeutic Itinerary; Mental illness; Conakry; Psychiatry service 


\section{Psychology \& Psychological Research International Journal}

\section{Introduction}

The therapeutic route is a movement of the patient and his entourage since the emergence of this new singularity that is the disease, until the end brought to it by the system of care to which the subject has access.

It denotes all the procedures involved in the therapeutic quest, from the appearance of disorders to their various sanctions. Five stages mark the therapeutic route of a subject and his relatives in a situation of illness: recognition, orientation to therapy, the diagnostic process, the healing ritual and the resultant [1].

In the early days of psychiatry, anthropological and psychopathological data were interspersed, which was an essential question. However, psycho pathologists have used anthropological facts only to confirm certain theoretical hypotheses. They have never taken cultural remedies for psychic disorders seriously [2]. Marcel Mauss in 1902 drew attention to the fact that magic was a technique and not a religion. He recognized the reality of ritual actions, asking himself the question of "the physical effect in the individual of the idea of death suggested by the community" [3]. In 1937, EVANS-PRICHARD published his famous monograph on the Zande of Sudan where he first showed how processes designated as therapeutic, were intimately entangled with the language, the world view and the organization of society [4]. Most of the patients said they were bewitched and this belief that we could have considered delusional was shared by the other members of the family, the clan, even the village. In developed countries, mental illness has developed a rational explanation and hence a well-codified management that takes into account the socio-cultural environment and is devolved to specialized institutions only: chemotherapy and psychotherapy form today the two complementary and inseparable aspects of this care taken in addition to social psychiatry, which considers the patient and his environment [5].

In Guadeloupe in 2005, a study by Patricia J et al, on cultural representations, the therapeutic route in infant mental health reported that $4 / 5$ of the families had taken personal remedies to help their children. These were preferentially of a cultural nature. In Africa, on the contrary, the weight of traditional beliefs remains very much alive and many irrational explanations remain about it, hence the multitude of care circuits [6]. In Gabon in 2006, a study by Dope Koumou R, et al. [7] on the care of the mentally ill in Libreville, reported a frequency of $20 \%$ of patients who came after attending various health care facilities. In Burkina Faso, in the same year Kapouné $\mathrm{K}$ in a retrospective study of 137 schizophrenic cases in the psychiatric ward of the university hospital of Yalgado Ouedraogo, reported $46,3 \%$ of cases who consulted at least once the traditional practitioner.

The itinerary of the patients is an important step to take into account in the care. In the case of mental illnesses in Africa, the route seems peculiar because of the social, false and tenacious prejudices erected as a real course of action [8]. In Côte d'Ivoire in 2009, Yavo PY, et al. [9], in their study of the therapeutic route of schizophrenics in Abidjan, reported $70.6 \%$ recourse to places of worship and $11.8 \%$ recourse to traditional healers. The lack of a specific prior study on the issue in Guinea, the various beliefs about mental illnesses sometimes requiring patients and their entourage to consult many care circuits, motivated the choice of this theme "Therapeutic itinerary of people suffering from mental illness in the psychiatric ward of Donka National Hospital, Conakry University Hospital "whose objectives were:

- To determine the frequency of persons suffering from mental illness admitted to the psychiatric ward from another health facility.

- To describe the socio-demographic characteristics of people with mental illness who have been to other care settings.

- To identify the different care circuits adopted by patients before their admission to the psychiatric ward of Donka National Hospital.

- To know the reasons for the choice of treatment and,

- To identify the methods of care.

\section{Methodology}

The Psychiatry Department of the Donka National Hospital CHU Conakry served as a framework for the realization of this study. It is the only referral center for the management of mental disorders and behavior, including cases of addiction in guinea. Our study focused on patients who had followed several therapeutic circuits. A questionnaire developed for this purpose served as a support for data collection. This was a prospective, descriptive study lasting 6 months (from November 1, 2014 to April 30, 2015). We conducted an exhaustive census of all patients meeting our inclusion criteria. We informed all the doctors in the department of the existence of the investigation. Patients and their relatives were received after obtaining their free and informed consent for 30-45 minutes; the questionnaire was completed by a single interviewer with the help of an 


\section{Psychology \& Psychological Research International Journal}

interpreter when necessary. The lack of precise information on the composition of traditional treatment has been our major difficulty for us [10-15].

\section{Results}

The frequency of people who used traditional medicine was $84 \%$, adolescents and young adults were much more affected. Male patients, singles were the most affected with a sex ratio (M / F) of 2.7 the majority was unemployed, and the secondary level was the most affected with respectively $45 \%, 24 \%, 18 \%, 13 \%$. The most common psychiatric comorbidities were: Bipolar Disorders (43.6\%), Psychoactive Substance Use (31.5\%) [16-19].

\section{Discussion}

We conducted a six-month prospective descriptive study of the Donka National Hospital Psychiatry Service from November 1, 2014 to April 30, 2015. The lack of precise information on the composition of the traditional treatment was the main difficulty; however we achieved the following results: During the study period, 518 patients were received in the service, of whom 380 resorted to other care circuits before admission to the psychiatric service, ie a hospital frequency of $73.3 \%$. In Mali in 2011 Sidibe F $[20,21]$ in his medical doctoral thesis on the study of therapeutic routes related to traditional medicine care reported a frequency of $12.31 \%$. In our series, the high frequency of patients who have resorted to other therapeutic circuits could be explained by the fact that in our societies, the majority of families first chose the traditional healers because of their attachment to cultural beliefs about Mental illness, modern services are only a last resort, after the failure of all other therapeutic remedies and the poor information of the population on mental health services in Guinea.

The age groups of 22 - 26 years, 27-31 years, were the most affected with frequencies of $28.9 \%, 27 \%$, cases and an average age of 28.5 years with extremes of 12 to 56 years old. Dope Koumou R, et al. [7] provided $41.6 \%$ of adolescents and young adults in their study on the care of the mentally ill in Libreville. The high rate of patients in these age groups could be explained by the fact that they are made up of adolescents and young adults who are most exposed to the stresses of daily life on the one hand, and On the other hand, it is the age groups of all hopes (active layer of society) from which the search for care across all circuits. In our study, we found a male predominance with $73 \%$ of cases compared to $27 \%$ of females, a sex ratio (M / F) of 2.7. This rate corroborates with some data from the literature [22,24]. Several reasons have been mentioned to explain this predominance of men, including the more restrictive social demands on the man pushing those around him to provide him with better access to care. As for socioprofessional categories, we found a predominance of patients without profession, i.e. $32.8 \%$ of cases followed by the formal training sector $22.6 \%$ of cases. The high frequency of patients without professions is due to the fact that the mental disorder is a factor of stigmatization and of socio-professional discrimination, which can favor either the abandonment of the professional activity or the rejection of the subjects if they wish to carry out a work or marginal integration.

The majority of our patients were single, $62.3 \%$ followed by $32 \%$ married couples. Our data conform to those described in the literature [25,27].

This predominance of singles is explained by the fact that these are young people whose onset of a psychological disorder compromises any marriage project. All levels of studies have been reached. The secondary level was the most affected with $45 \%$ of cases, against $24 \%$ for the higher level, $18 \%$ for the primary level, and $13 \%$ for those without levels. In contrast to our study Athanase $\mathrm{M}$, et al [28] reported $66 \%$ for those without levels, $44 \%$ for the primary level, $29 \%$ for the secondary level, and $6 \%$ for the upper level. The predominance of the secondary level is explained by the fact that this level corresponds to the age of the great adolescence which corresponds to the period of appearance of the mental diseases. The largest numbers of our patients, $80 \%$ of cases were from low Guinea, followed by the average and high guinea $8 \%$, guinea forest $2 \%$. This high rate of patients coming from low guinea would be due to the presence of the psychiatric service in Conakry, which is the only national reference center of the country, for the management of mental disorders and including addictions. Many of our patients had a personal psychiatric history of $53 \%$ of cases, compared with $47 \%$ of our patients with no personal psychiatric history. This high rate could be explained by the fact that half of our patients were readmitted for recurrences frequently related to either the use of psychoactive substances, or breakage or poor compliance with care or failure of traditional treatment. Most of our patients reported using traditional medicine during their illness, $84 \%$ followed by modern medicine $10 \%$, and places of prayer $6 \%$. These different structures can be consulted simultaneously and cyclically; this itinerary is 


\section{Psychology \& Psychological Research International Journal}

described as a "therapeutic adventure" involving the group, that is, the family, which is often the decisionmaking body in the choice of the care circuit.

More than half of our patients came to a psychiatric consultation on the advice of a loved one, or because of the failure of traditional and religious treatment, respectively $67 \%$, 33\%. Koumou $R$, et al. [7] reported in their study of the different therapeutic circuits, that the motivations of choice of the psychiatric hospital were related to the failure of the traditional and / or religious treatment is $67 \%$, or on advice of a close $31.8 \%$. These high frequencies could be explained by the fact that in Africa, the weight of traditional beliefs remains very strong and many irrational explanations remain about it, hence the multitude of care circuits.

In the psychiatric hospital, drug treatment consisting of the administration of neuroleptics is $62.6 \%$, followed by thymoregulators $44 \%$, psychotherapy was indicated in $38.9 \%$, it is an individual psychotherapy and Support. The high frequency of neuroleptics and mood stabilizers is explained by the fact that the majority of our patients responded to the properties of uses of its drugs namely delirium, hallucinations, psychomotor agitation, exaltation of mood, and other associated signs on the one hand, and their presentation in the generic form with a lower cost.

The treatment in traditional healers and religious consisted in the administration of herbal drinks 49.2\%, the talisman $78.9 \%$, immersion in the steam baths $24.2 \%$, the sacrifice of animals $32.8 \%$, the compression and the flogging were used for the most agitated is $14.7 \%$, against it was observed a simultaneous care in hospitalized patients is $1.3 \%$. This finding is shared by most authors [29,30]. Ekomy and Moukouta believe that traditional medicine still occupies a place of choice in the provision of care [31,32]. It is therefore necessary to combine tradition and modern psychiatry for better care [33]. This high frequency of recourse to the care of traditional healers and / or religious is explained by the fact that some traditherapeutes use the side effects to medical treatment: drowsiness, gaze cap, torticollis, heaviness of the tongue, stiffness, the trembling of the extremities, the dryness of the mouth, to devalue the treatment proposed by the psychiatrist for their benefit and even require the patients to abandon it. This same behavior is encountered in places of prayer. The disadvantage induced by these different therapies is the fact that traditional healers are mainly oriented towards finding the culprit; their activity consists in identifying the accused and taken as responsible for the evil to oblige them to confess and to be reconciled with the victim. Muslims are mostly represented in this study, i.e. $89 \%$ against $11 \%$. This high rate of Muslims in our study is explained by the fact that the plurality of the Guinean population is Muslim.

The diagnoses of bipolar disorder, psychoactive substance use and delirious puffing were the most frequent, $43.6 \%, 31.5 \%$ and $12.3 \%$ respectively; cases. These data are comparable to those described in the literature $[34,35]$. The high frequencies of psychiatric disorders could be explained by the fact that they generally start during adolescence or early adulthood on the one hand, and the notion of substance abuse is a risk factor in the occurrence of these disorders.

Many of our patients had no satisfaction with the services provided by traditional healers, i.e. $67 \%$, followed by $20 \%$ with few satisfactions, and $13 \%$ with satisfaction. This high frequency of non-satisfaction in this study could be explained by the fact that the traditional mechanisms (sacrifice, consultation with the healer) and those inherited from religion (prayer, talisman ...) after a relatively long period will sometimes prove powerless to subtract the individual from the isolation in which he gradually sinks. Disappointed, discouraged patients and their families then move to the psychiatric hospital in search of a therapeutic ideal.

During our study, the most predominant reasons for consultation were instinctual disorders (50.5\%), followed by psychomotor disorders (46\%) and thought disorders (34.4\%). These data conform to those described in the literature [36,38]. This predominance is related to spiritual problems, and the etiologies most evoked remain the spell (witch etiology) and drug addiction.

In our study, we noticed that most of our patients were received outpatients or in hospital with a progression less than or equal to 6 months or $65 \%$ of cases, followed by $35 \%$ whose evolution was greater than 6 months. This acute or chronic evolution of certain affections pushes our patients to cling to all promising speeches.

\section{References}

1. Guilty JM, Okemba-Ngouet P, Gaborit De Montjou L, et al. (1992) Therapeutic route change and identity: the example of Central Africa. Medical Psychology 24(1): 21-23. 


\section{Psychology \& Psychological Research International Journal}

2. Taboa (2001) Sorcery and psychiatric expertise in the Central African Republic: about a case of intramural drama. Memory for the DU of forensic psychiatry, Paris-sud, pp: 36.

3. Marcel Mauss (1973) Physical effect in the individual of the idea of death suggested by the community (Australia, New Zealand) from the journal of normal and pathological psychology, 1926. Communication presented to the society of psychology. IN: Sociology and Anthropology. Paris: PUF, pp: 312-330.

4. Evans -Pritchard EE (1972) Sorcery, oral and magic among Azande. Paris: Gallimard

5. Mboussou M, Ngabolo G (2005) Between two cultures: the therapeutic choice. Rib 18(5): 33-36.

6. Patricia J, Ovilivier T, Tahar A (2005) Cultural representations, therapeutic itinerary and infant mental health in Guadeloupe. Psychiatry of the child 47(2): 537-575.

7. Dope KR, Mboussou M, Mbungu F (2009) Management of mental patients in Libreville: the different therapeutic circuits. Medicine of Black Africa 56(11): 573-579.

8. Kapoune $\mathrm{K}$ Therapeutic route of mental illness in Africa: The case of schizophrenia in Burkina Fasso: psychiatry causes N 53: 21-25.

9. Yavo PY, Yessonguilana JMYT, Catherine Assi-Sedji (2009) Therapeutic itinerary of schizophrenics in ABIDJAN, psychiatric information 85(5): 461-469.

10. Dr Xiaoni Zhang (2000) traditional medicine: WHO definition / GENEVA.

11. HTTPS: // en.wikipedia.Org / wiki, 5/5/2015, 16h37min.

12. http: //: rsmq .cam .org / smq / journals / v 23 n 2 .htm, 9/5/2015, 11h 45min.

13. Zempleni A (1985) "Disease" and its "causes", introduction, ethnography 2:13-44.

14. Sindzingr N (1984) The necessity of meaning: the explanation of misfortune among the Senufo, the meaning of evil: anthropology, history, sociology of illness, Paris, Edition des archives contemporariness 93-122.
15. Augue M (1986) Anthropology of the disease, the man 97-98(26): 81-90.

16. Moro Mr (1994) parent in exile. Psychology and migration, Paris, PUE, 2001.

17. Pedinielli JL (1996) etiological theories of patients. French psychology 41(2): 137-145.

18. Wess MG (1997) explanatory model interview (EMIE): Framework for Comparative Study of Illness, Transcultural. Psychiatry 34(2): 235-263.

19. Wess MG (2001) Cultural Epidemiology: An Introduction and Overview, Anthropology, and Medicine, 8(1): 5-29.

20. Mbadinga S, Ngabol G, Mboussou M (2002) Caring in circles: on the Front of the sharing of the therapeutic space in black Africa .Nervure 15(1): 22-25.

21. Famoussa Sidibe M (2010) Study of therapeutic routes related to traditional medicine care in the households of the commune $\mathrm{V}$ of the district of BAMAKO, MALI: case of the district of sabalibougou. $\mathrm{PhD}$ Thesis in Medicine 47.

22. Ferenczi S (1985-1932) journal Clinique. Paris, Payot.

23. Tisseron S (1992) Shame, psychoanalysis of a social bond. Paris, Dunod.

24. Zempleni A (1969) Traditional therapy of mental disorders in Wolof and Lelous (Senegal). Soc. SCI. And Med 3: 191-205.

25. Rey JM, Ktiouet I, Paes M (2009) Drug abuse in Morocco in figures. Doctor's notebooks February 1999: 17.

26. Yao YP: delusional psychosis: epidemiological and clinical aspects, doctoral thesis in medicine, EHD, INSP, ABIDJAN pp: 78-79.

27. Dallo S, Delicious Boufee (2004) Epidemiology and clinical aspects in the psychiatric ward of the Donka National Hospital CHU Conakry. Doctoral thesis in medicine, Conakry pp: 48.

28. Millogo A, Traore De (2001) study of mental health knowledge in schools at Bobo-Dioulasso (Burkina Fasso) 13: 103-107. 


\section{Psychology \& Psychological Research International Journal}

29. Ouedraogo A (1993) Place of traditherapeutes in health care in Burkina rib 5: 44-48.

30. Bensmail (1984) Belkacem traditional psychiatry and magical practices. Medical Psychology, Frenchlanguage Medical Psychology Society. Paris 12091212.

31. Ekomy Dl (2005) The psycho-emotional experience of HIV carriers. Doctoral Thesis in Medicine, Faculty of Medicine, GABON University of Health Sciences 460: 49-65.

32. Moukouta SC, Pewzner-Apeloig E (2002) Traditional therapies, modern therapies in psychiatric environment in CONGO. Syncretism or interference. Medical-Psychological Annals 160(5-6): 354-360.

33. Halle A, Gueye M, Sarrd (1995) Peculiar aspects of psychiatry in Africa: encounter between two systems of care. Psychiatric Information 71: 535.
34. Bonnet D (1982) The MOSSI of high-volta: biological body social body. Thesis of 3rd cycle of social sciences. Parie N 344: 329-346.

35. Devereux G (1975) Culture and symptomatology. Psychiatric news Parie 2: 12-17.

36. Kette CG (2003) Study of the therapeutic routes taken by the mentally ill seen in the psychiatric ward. Thesis for the doctorate in state-certified medicine. Bangui 93.

37. Arpin JA (1992) The cultural identity of the clinician and his role in his relationship with the patient, mental health in Quebec 18(2): 99-112.

38. Trincaz J (1973) Myths, Meanings and Representations in Mancagnes of Casamance, African Psychopathology 9(1): 79-100. 